\title{
Formation of conceptual foundations for modeling the organizational structures of agricultural entities based on multilevel cooperation
}

\author{
Sergey Pestrikov ${ }^{1,2^{*}}$, Dmitry Maltsev ${ }^{1,2}$, and Elena Gureeva ${ }^{2}$ \\ Perm State Agrarian and Technological University named after academician D.N. Pryanishnikova, 614990, Perm, Russia \\ Perm National Research Polytechnic University, 614990, Perm, Russia
}

\begin{abstract}
The article presents an analysis of the organizational structures of cooperatives in the agricultural industry, offers conceptual approaches to modeling the organizational structures of agricultural formations in Russia, taking into account the specifics of the industry, using modern and innovative strategies for organizational changes. The creation of flexible multilevel systems of cooperation is substantiated, allowing, on the one hand, to consider the interests of both members of a single cooperative and a group of cooperatives that synergistically consolidate the available and attracted resources. An assessment of the importance of these principles for creating an effective cooperative structure is based on analyzing a survey of peasant farms in the Perm Territory. A promising organizational structure of multilevel cooperation has been developed.
\end{abstract}

\section{Introduction}

Topical issues of organizational excellence affect many sectors of the national economy [1]. However, as a rule, the most inert processes do not reflect the dynamics of rapid changes in the economy and proceed during the formation of complex organizational structures. For example, such complex structures include cooperatives, clusters, holdings. That is why in recent years, researchers have been looking at issues of analyzing the quality, adequacy, levels, and dynamics of development of organizational structures, the use of structures of a new type. These structures offer "soft" forms, on the one hand, and ensuring the manageability of organizational structures, on the other hand [2].

The system of agricultural cooperation in Russia began to revive again in the early 1990s after the adoption of the federal law "On Agricultural Cooperation." However, slipping in this direction is visible to the naked eye. It is evident to everyone that the role of cooperative formations in the country's economy should grow. Thus, the number of successful cooperatives in the western and eastern economies is significant (Valio, Mondragon, HKScan).

In Russia, the revival of agricultural cooperation is undoubtedly a priority task of the state since it guarantees the country's food security. Russian government realized the priority of the development of small forms of farming and rural cooperation. The state has developed and approved a Resolution of the Government of the Russian Federation, which provides funds for the creation of a support system for farmers and the development of rural cooperation in the period from 2019 to 2024 in the amount of 37.368 billion rubles [3].

There are examples of the successful operation of cooperative structures in the Lipetsk region, Tatarstan, and the Tyumen region in Russia. Despite the existing examples of the successful operation of cooperative structures in the country, the overall result of their activities on a national scale is indisputably low. In parallel with the cooperative policy in the country's agriculture, the creation and development of cluster associations are observed as one of the forms contributing to the synergistic manifestations of complex organizational services. However, there is still no broad clustering of all spheres of the agro-industrial complex, and little attention is paid to their interaction at the regional level. An extensive experience of cluster activity has been accumulated in specific industries.

However, the transfer and adaptation of this experience, taking into account the specifics of the agroindustrial complex, is not carried out. In addition, the investment attractiveness of such activities remains extremely low, both due to bureaucratic procedures and due to the lack of innovation and qualified personnel [4].

One of the goals of modeling organizational structures is to predict the leading economic indicators of a cluster using regression analysis methods [5]. Efficiency assessment is shown on the example of the analysis of the activities of agricultural enterprises in the Lipetsk region [5]. In work [4], a model of a livestock cluster in meat and dairy and food complexes is proposed on the example of the Saratov region. The model assumes the presence of a cluster core, which will

\footnotetext{
*Corresponding author: pestrikovsa@mail.ru
} 
directly deal with animal husbandry, under the supervision of the executive authorities.

On the one hand, this work is joint work with the regional duma on organizing personnel training, conducting research, and attracting funding. On the other hand, this work is interaction with service companies in the field of legal support, transport companies, suppliers of machinery and equipment, feed. It is predicted that the introduction of the cluster will presumably reduce the costs of commodity circulation of products by $29.8 \%$ for meat and meat products and by $26 \%$ for milk and dairy products.

Obviously, this model is significantly enlarged and does not consider many factors: technical, technological, weather and climatic, socio-demographic, and other factors. A detailed analysis of this problem can be found in [6]. It is indicated that the organizational and legal forms of enterprises that are part of the cluster can significantly impact financial performance. Thus, according to the results of studies carried out in the EU, using the example of the Slovak Republic [7], the following was established: commercial organizations have more assets, higher creditworthiness, and investment attractiveness (by about 20\%) compared to cooperatives. In this case, it is also necessary to consider the level of government support in different countries. For example, since 2019, the emphasis has shifted to supporting agricultural cooperatives in Russia. The introduction of joint-stock cooperation as an innovation in the management system of agricultural enterprises is also seen as promising [8].

Transport logistics cause significant difficulties, which is due both to the large distances between manufacturers and consumers and the fact that the products are perishable and require special transportation conditions. In [9], based on the analysis of the activities of 36 transport companies in China, a strategy for delivering agro-industrial products to consumers is proposed.

Similar difficulties are typical for the countries of Latin America. Thus, in [10], using the Crespo region (Argentina) example, a scheme of interaction between enterprises of the agro-industrial complex is presented, and a centralized model of interaction of all stakeholders through a regional agricultural cooperative is proposed.

These shortcomings are due to a poorly developed, ineffective organizational structure. Therefore, we need new approaches to their formation, taking into account the totality of all significant factors. Important questions of the methodology for modeling the organizational structures of agricultural formations remain not disclosed and cannot be used in practice accordingly.

The purpose of this article is to propose conceptual approaches to modeling the organizational structures of agricultural formations in Russia, taking into account the specifics of the industry, using modern and innovative strategies for organizational change.

\section{Materials and methods}

Conceptual problems of modeling organizational structures are in the area of close attention of scientists and specialists. The reason is the rapid changes in external and internal factors. External factors are socioeconomic shocks in the form of the spread of coronavirus infection, which took the lives of millions of people and put the stability and resilience of many economies on the line. However, the reason is also in internal factors that can either accelerate the development of complex organizations or negate the implementation of opportunities associated with the synergy effect of improving structural units.

A feature of the current state of the agricultural industry in Russia, as a complex socio-economic system, is the need to adjust the industry structure based on innovative processes that allow actively building effective organizational structures. Today, in the agroindustrial complex of the Russian Federation, processes are taking place aimed at the development of cooperation, which is supported both "from below" and "from above." However, the dominant is the latter option.

So, J. Schumpeter singled out entrepreneurship as the main driving force of the economy. The entrepreneur relies on a general framework set by state institutions. An entrepreneur is an innovator who identifies opportunities for further business development. In this process, the entrepreneur, according to J. Schumpeter, implements the function of "new combinations of production factors" [11]. Among these functions, organizational and economic innovation is through the institution of economic activity of entrepreneurship, including through associations of entrepreneurs. The importance of this organizational and economic innovation is emphasized [12]. This fact means that entrepreneurs can determine the possibility and necessity of forming unifying structures to realize common goals. Thus, cooperatives can become the most effective instrument, functioning on the principles of initiative and independence. The creation of an appropriate business environment becomes a prerequisite.

It should be noted that such complex organizational structures (when they are formed "from below") often do not have effective management. There are not enough financial resources, managerial potential, complicated internal processes of interaction between the subjects of the structure). In the second variant of the development of cooperation, namely with direct support at the level of Heads of regions, line ministries, the organizational structure of agricultural formations takes on a more structurally consistent look, but, in our opinion, with elements of standard administrative management.

Stop factors restrain the development of agricultural cooperation. Stop factors are the insufficient level of the necessary competencies of both state bodies and agricultural entities, the lack of developed cooperative infrastructure and the small number of successful cooperative projects, and the difficulty of maintaining regular activities in monopolizing the agricultural market. This factor is also retail and, in many regions, 
the dominant presence of prominent market players. For example, in the Perm Territory, the UKMP group of companies has about $75 \%$ of the share of raw milk processing. In addition, socio-psychological factors associated with distrust of repeated forms of cooperation in Russia also negatively impact. The existing forms of cooperation have not brought significant positive results for the cooperation and industry members as a whole.

Consequently, a new methodology is needed for the formation of organizational structures of agricultural formations. One way to resolve the issue is to create flexible multi-level cooperation systems, allowing to consider the interests of both members of a single cooperative and a group of cooperatives that synergistically consolidate the available and attracted resources. The experience of the successful operation of the Lipetsk region is known [13].

\section{Results and discussion}

Thus, the organizational structure should be flexible and adaptable. Not only self-organized but striving for selfdevelopment. Thus, the Perm School of Innovation Management is based on the following position: A.V. Molodchik, S.V. Komarov, N.B. Akatov and other researchers. In this methodology, the pivot is the $2 \mathrm{C}$ system based on self-development processes.

Let us highlight the key approaches in the formation of $2 \mathrm{C}$ systems.

1. People's behavior is focused on the priority of their internal motivation through the processes of selfdevelopment and self-organization.

2. Through the mechanisms of the tension theory, the organization seeks to innovate, gaining some competitive advantage by reducing the potential difference between the desired result and the tense goals.

3. Transition to a self-developing business model based on the principles of organizational excellence.

4. Leadership is a key factor for the formation of competencies in 2C systems [14].

We are in solidarity with the positions of those authors who reveal the development of organizational forms through their multiplicity. There is an urgent need to have numerous effective organizational forms and consider the social nature of their activities [15]. At present, the issue of forming the development of such structures has not been sufficiently worked out.

The state policy in the field of cooperation in agriculture has not been fully implemented. Related bodies for the development of cooperation have been created in each region. Organizational innovations, in our opinion, do not imply a rigid structure and stereotyped, and a new organizational structure should be built on the following fundamental principles:

1. self-organization and self-development,

2. much variance,

3. flexibility and adaptability,

4. initiative and independence,

5. dominant leadership and trust,

6. clarity and transparency of the goals,

7. clustering 8 . adequacy of government support,

9. competence of state bodies.

An assessment of the importance of these principles for creating an effective cooperative structure is based on a survey of 24 peasant farms in the Perm Territory. Each of the nine principles was assessed on a five-point scale ( 1 - not significant, 5 - very significant). Figure 1 shows the results of this study.

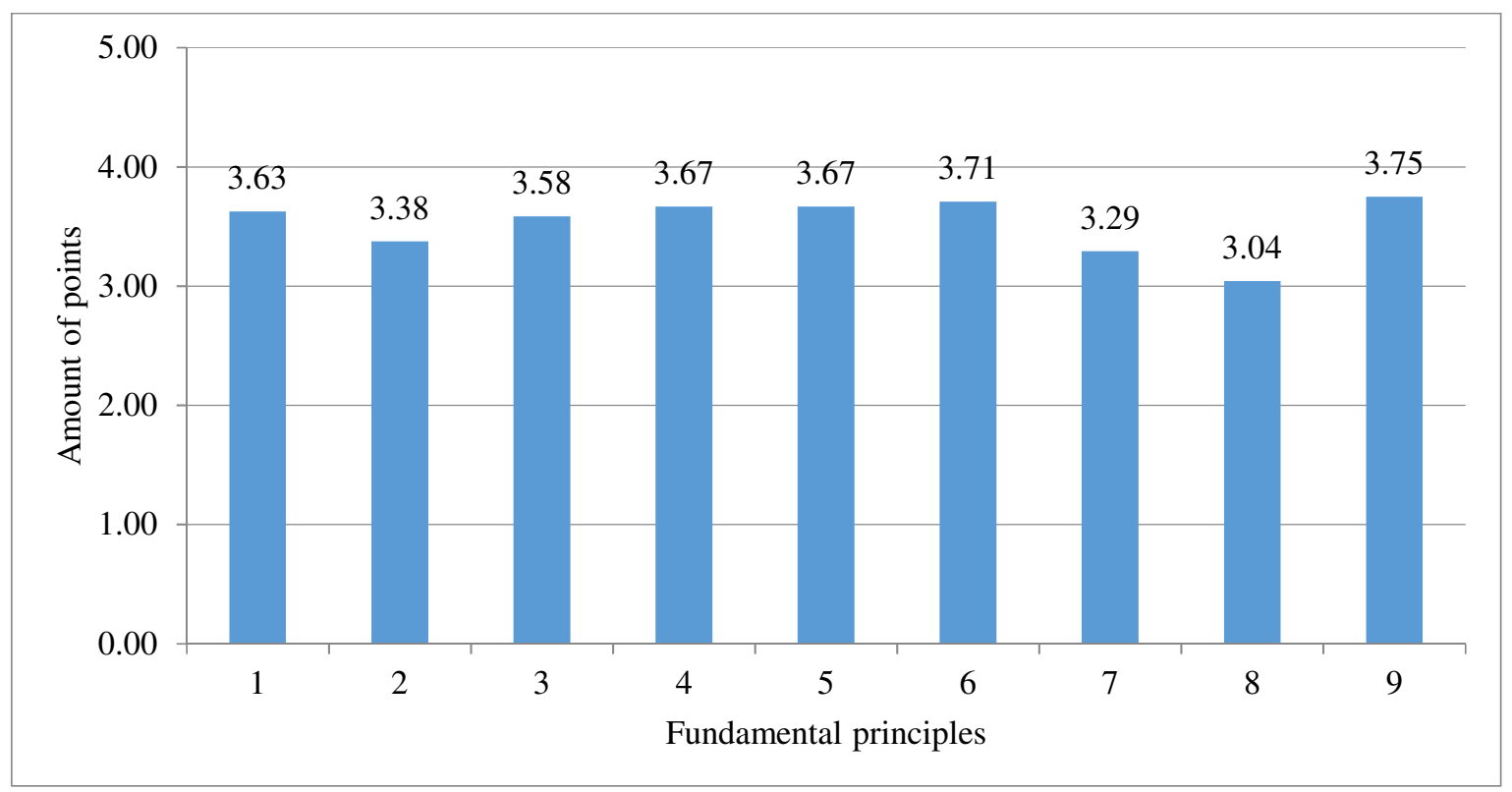

Figure 1. Results of the assessment of the fundamental principles of peasant farming: 1 - self-organization and selfdevelopment; 2 - much variation; 3 - flexibility and adaptability; 4 - initiative and independence; 5 - dominant leadership and trust; 6 - clarity and transparency of the goals; 7 - clustering; 8 - sufficiency of state support; 9 competence of state bodies. 
Based on the above principles of building an organizational structure, the following promising cooperation model is proposed (Fig. 2).

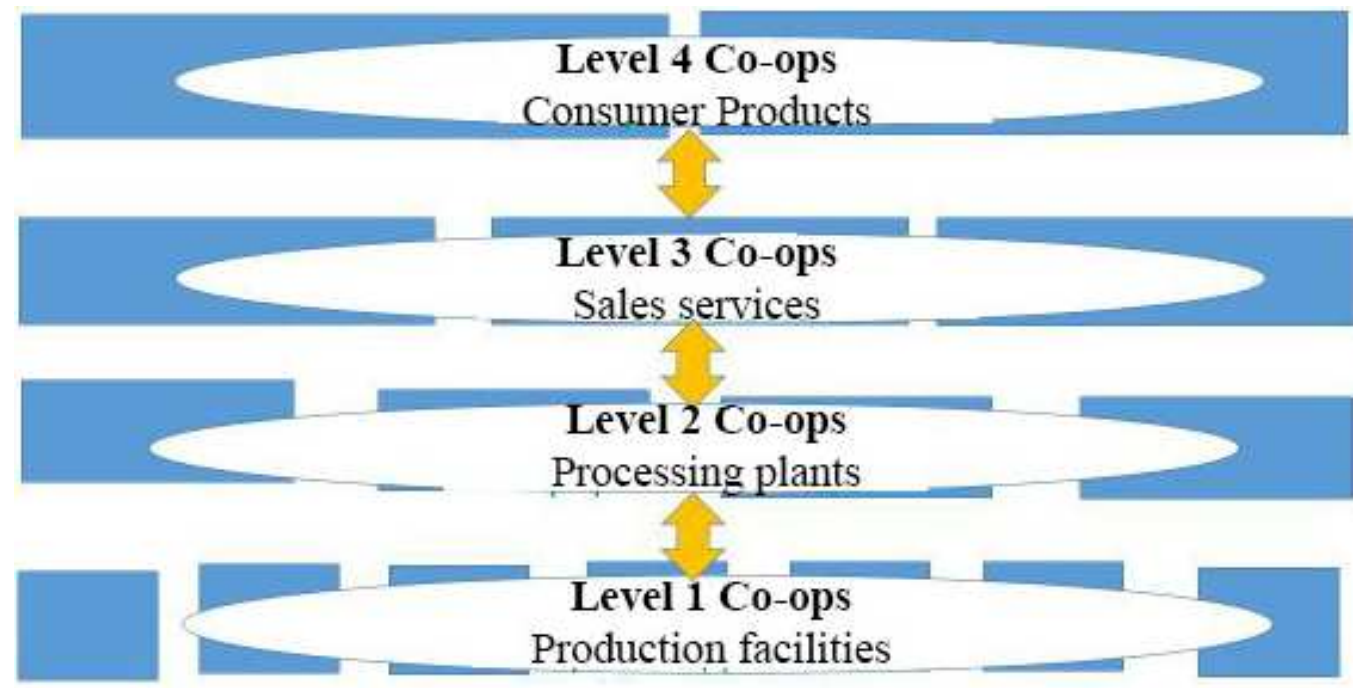

Figure 2.The perspective organizational structure of multilevel cooperation.

\section{Conclusion}

A feature of the current state of such a complex socioeconomic system as the agricultural industry in Russia is the need to adjust the industry structure based on innovative processes that actively build effective organizational structures. Today in the agro-industrial complex of the Russian Federation, processes are taking place aimed at the development of cooperation, which is supported both "from below" and "from above," but the dominant is the latter option.

It is necessary to form a new conceptual approach to the criteria for forming complex organizational structures and measuring the results of the formation of cooperative relationships of self-sustaining structures of cooperative cluster formations

\section{References}

1. S.A. Pestrikov, S.Yu.Tyulkina, Schumpeterianreading: Proceedings of the 3rd International Scientific and Practical Conference, (Perm, 2013)

2. E.S. Mishchenko, Organizational management structures (Tambov, 2011)

3. Presidium of the Council under the President of the Russian Federation for Strategic Development and National Projects, N 16 Passport of the national project "Small and Medium Enterprises and Support for Individual Entrepreneurial Initiatives" (2018)

4. E. A. Aleshina, E. I. Anisimova, D. V. Serdobintsev, IOP Conf. Ser.: Earth Environ. Sci. 459062018 (2020).

5. N. Y. Timofeeva International Journal of Engineering and Technology, 7, (2018).

6. O. Isaeva, M. Kabanenko, A. Chistyakov, L. Dubrova, N. Filin, E3S Web of Conferences.
175.

13022.

(2020).

10.1051/e3sconf/202017513022.

7. I. KravčákováVozárová, R. Kotulič, R. Vavrek, Applied Economics, 51:56, 5999-6008, (2019) DOI: 10.1080/00036846.2019.1645285

8. L. Xiao, International Journal of Security and Its Applications 10 (3) pp.333-344 (2016)

9. C. Han, A. Pervez, J. Wu, X. Shen, D. Zhang, Sustainability 12(16), 6547; (2020) https://doi.org/10.3390/su12166547

10. R. SolenoWilches, Cambiosestructurales $e$ institucionales delcooperativismo agrícola entrerrianoen la postconvertibilidad. (2017).

11. J. Schumpeter The theory of economic development: a study of entrepreneurial profit, capital, credit, interest and the conjuncture cycle. (1982)

12. E.V. Antipina The innovative concept of entrepreneurship by J. Schumpeter (2014).

13. R.G. Yanbykh, A.V. Morozov, G.I. Yavkina On the Development of Agricultural Consumer Cooperation in Russia (2014)

14. S.V. Komarov From self-organization to selfdevelopment: a change in the management paradigm. (Yekaterinburg, 2013)

15. L.V. Obedkova Improving the management system of cooperative and structures in modern Russia (2011). 